\title{
Impact Factor of the journal or citation to the articles for evaluating the
}

\section{curriculum vita of a researcher}

\author{
Sathian B1, Sreedharan J2, Banerjee I3, Roy B4, Chandrasekharan N5
}

${ }^{1}$ Assistant Professor, Department of Community Medicine, Manipal College of Medical Sciences, Pokhara, Nepal

${ }^{2}$ Assistant Director, Research Division, Gulf Medical University, Ajman, UAE.

${ }^{3}$ Lecturer, Department of Pharmacology, Manipal College of Medical Sciences, Pokhara, Nepal

${ }^{4}$ Assistant Professor, Department of Physiology, Manipal College of Medical Sciences, Pokhara, Nepal.

${ }^{5}$ Lecturer, Department of Orthopaedics, Gulf Medical University, Ajman, UAE.

\section{Chief Editor}

\section{Dr. Abhilash E S}

Technical Editor

Dr. Nishida Chandrasekharan

Formatting Editor

Dr. Indrajit Banerjee

This title
is indexed
in SciVerse
Scopus
Improving research
results through
analytical power

\section{Editorial}

\section{Corresponding Author}

Dr. Brijesh Sathian

Assistant Professor,

Department of Community Medicine

Manipal College of Medical Sciences

Pokhara, Nepal

Email- drsathian@gmail.com

\section{Editorial}

"Some scientists "published research article" will be having lots of "citations" but it might not be published in a "high impact factor journal". There is no value for these scientists?

\section{Impact Factor}

An Impact Factor is one of the measurements of the relative importance of a journal, individual article, or researcher to literature and research.

Calculation for impact factor revised to exclude selfcitations $^{1,2,3}$

$A=$ citations in 1992 to articles published in 1990-91

$B=1992$ self-citations to articles published in 1990-91

$C=A-B=$ total citations minus self-citations to recent articles

$D=$ number of articles published 1990-91

$E=$ revised impact factor (C/D)

\section{Citations}

Citations to publications [This is the number of citations to all publications], $h$-index of researchers [h-index is the largest number $h$ such that $h$ publications have at least $h$ citations], i10-index [i10-index is the number of publications with at least 10 citations] and journal impact factors are 
used to measure the importance and impact of research ${ }^{4,5}$.

\section{Importance of citation analysis}

1. Promotions and tenure of the scientists/ academicians when a limited number of higher posts with several applicants.

2. Scientifically document and quantify the impact of the research done by the researcher.

3. While applying research grants for submitting to different funding agencies for justification to the quality of the researcher to avail grants.

4. To find out whether the research is relevant to the community or rest of the world and other scientists (Generalisation of the research).

\section{Important points to remember while evaluating a CV}

1. Sometimes the number of times the article cited is not a merit of the article. Eg It is seen that a paper with plagiarism cited several times by several authors. Other instance a bad quality article is criticised by several authors. Both the cases journal and the researcher who published the bad work got benefited.

2. Some of the methods used to evaluate citations will not consider the citations by books and thesis.

3. Some disciplines like law, humanities have low number of journals compared to medicine so while comparing a researchers between these two disciplines will give wrong impact so better to compare the researchers from same discipline.

4. Whenever review articles are taking into account it will boost the citation of the researcher compared to a research article. So, a researcher published few good review articles can get more citations compared to a scientist who published very good research articles.

5. Some of the researchers do self citation for getting visibility to their research work which can falsify the evaluation.

6. One should read the available best resources related to impact factor and citations before evaluating the $\mathrm{CV}^{1-16}$.

Sources for getting information regarding the citations of a published research article

1. Web of Science

2. Scopus

3. Google Scholar

4. Academic Search Premier

5. Business Source Premier

6. CINAHL

7. PsycINFO

8. PubMed Central

9. Science Direct

\section{Suggestions}

1. For a young researcher who is trying to get funds for his higher education or projects better to use the impact factor of the journal where he published his works.
2. For a senior academician or scientist it is better to use $\mathrm{H}$ index, i10 index, and the total number of citations excluding the self citations. It is very difficult to get lots of citations for a young researcher who recently started publishing his works however the work will be excellent.

\section{Conclusion:}

CV bibliography of the scientists/ researchers should emphasise not only the Impact Factor of the journal published but also the citations to the articles. We must be aware that many of the high impact journals are paid journals; it will be difficult for a brilliant researcher who has less funds and resources to afford that. Best way to increase the citations are publishing the article in a open access journal and other method is to become a member of the Professional network for scientists and researchers like research gate, Researcher ID, Epernicus Network, Academia.edu, Scholar Universe.

\section{Conflict of interest:}

There is no conflict of interest among authors arising from the study.

\section{References:}

1. The Thomson Reuters Impact Factor - IP \& Science Thomson Reuters [Internet]. [online] 1994 [cited 2013 Dec 11]. Available from: http://wokinfo.com/essays/impactfactor/

2. $\mathrm{SCl}^{\circledR}$ Journal Citation Reports ${ }^{\circledR}$ : a bibliometric analysis of science journals in the $|S|^{\circledR}$ database. Philadelphia: Institute for Scientific Information, Inc. ${ }^{\circledR}, 1993$.

3. Garfield E. Citation analysis as a tool in journal evaluation. Science 178:471-9, 1972.

4. Welcome - Research Impact Factors - Library Guides at University of Canberra [Internet]. [cited 2013 Dec 11]. Available from: http://canberra.libguides.com/content.php?pid=157360.

5. Hirsch JE. An index to quantify an individual's scientific research output. Proceedings of the National Academy of Sciences of the United States of America. 2005;102(46): 16569-16572.

6. Moed HF: Measuring contextual citation impact of scientific journals. J Informetr 2010, 4:265-277.

7. van der Wall EE: Journal impact factor: Holy Grail? Neth Heart J 2012, 20:385-386.

8. Johnson $\mathrm{MH}$, Cohen J, Grudzinskas G: The uses and abuses of bibliometrics. Reprod Biomed Online 2012, 24:485-486.

9. Pierce GN: Too much impact for the impact factor: Are a new generation of scientists in peril? [in English and French]. Can J Physiol Pharmacol 2012, 90:iii-iv.

10. Waheed U, Satti HS: The impact factor: a bad impact on individual research. Health Educ J 2012, 71:253-254.

11. Seglen PO: Why the impact factor of journals should not be used for evaluating research. BMJ 1997, 314:498-502.

12. Kulkarni AV, Busse JW, Shams I: Characteristics associated with citation rate of the medical literature. PLoS One 2007, 2:e403.

13. Callaham $\mathrm{M}$, Wears $\mathrm{RL}$, Weber $\mathrm{E}$ : Journal prestige, 
publication bias, and other characteristics associated with citation of published studies in peer-reviewed journals. JAMA 2002, 287:2847-2850.

14. Weale AR, Bailey M, Lear PA: The level of non-citation of articles within a journal as a measure of quality: a comparison to the impact factor. BMC Med Res Methodol 2004, 4:14.

15. Patsopoulos NA, Analatos AA, loannidis JP: Relative citation impact of various study designs in the health sciences. JAMA 2005, 293:2362-2366.

16. Figg WD, Dunn L, Liewehr DJ, Steinberg SM, Thurman PW, Barrett JC, Birkinshaw J: Scientific collaboration results in higher citation rates of published articles. Pharmacotherapy 2006, 26:759-767.

\begin{tabular}{|l|c|}
\hline \multicolumn{2}{|c|}{ Article Information } \\
\hline \multicolumn{2}{|c|}{ Article history } \\
\hline Received & $15^{\text {th }}$ December 2013 \\
\hline Received in revised form & $22^{\text {nd }}$ December2013 \\
\hline Accepted & $31^{\text {tt }}$ December2013 \\
\hline
\end{tabular}

